\title{
Aprendizagem colaborativa e conectivismo pedagógico no Facebook
}

\author{
Adriana Alves Novais Souza1, Henrique Nou Schneider2 \\ 1Mestra em Educação - Universidade Federal de Sergipe (UFS), professor da rede pública \\ estadual de Sergipe \\ 2Professor do Núcleo de Pós-graduação em Educação e do DCOMP - Universidade Federal \\ de Sergipe (UFS), coordenador do Grupo de Estudo e Pesquisa em Informática na Educação \\ (GEPIED) UFS/CNPq \\ dria.novais.souza@gmail.com, hnseterra.com.br
}

\begin{abstract}
The article discusses the theoretical foundations that underlie learning and communication within the context of an experience with use of the Facebook social networking platform, whose problem lies in the way the teacher can take ownership of the convergence of media resources provided by online social networks promote a more effective learning and what are the main difficulties faced in its realization. The data presented are from a Master's dissertation that deals with the pedagogical praxis mediated Connectivism, using as a social networking platform Facebook, emphasizing the vision of the future teachers in the use of technology in the process.
\end{abstract}

Resumo. $O$ artigo discute as bases teóricas que fundamentam a aprendizagem $e$ comunicação dentro do contexto de uma experiência com uso da plataforma de rede social Facebook, cuja problemática está situada na forma como o professor pode se apropriar da convergência de recursos midiáticos proporcionada pelas redes sociais online a fim de promover uma aprendizagem mais efetiva e quais as principais dificuldades enfrentadas em sua realização. Os dados apresentados são oriundos de uma dissertação de Mestrado que trata da práxis pedagógica mediada pelo conectivismo, utilizando como plataforma de redes sociais o Facebook, enfatizando a visão dos futuros docentes quanto à utilização das tecnologias no processo.

\section{Introdução}

Pensar a prática docente com foco no processo de aprendizagem do aluno não é uma proposta recente e tem sido alvo de discussões e fomentado a criação de diversas teorias, embora sob diferentes nomenclaturas: aprendizagem interacionista, significativa, construtivista, colaborativa, dentre outras. Tais discussões continuam em vigor nos debates educacionais atuais, através de propostas didáticas que propõem a desconstrução do papel do professor como "doador" do conhecimento para o daquele que constrói junto com o aluno, que propõe perguntas e incentiva a busca por respostas, num processo constante de construção de saberes de forma partilhada.

Segundo Schön [2000, p. 189], "os seres humanos, em sua interação com o outro, constroem um design de seu comportamento e dispõem de teorias para fazê-lo", as quais incluem "os valores, as estratégias e os pressupostos básicos que informam os padrões de comportamento interpessoal dos indivíduos". Com isso, defende-se a fundamentação teórica da prática pedagógica dentro das perspectivas de aprendizagem da atualidade, pois é na correlação teoria-prática que o professor encontra os caminhos que o levam ao efetivo exercício da docência. 
Dessa forma, buscou-se apresentar, neste artigo, dados de uma pesquisa realizada para uma dissertação de mestrado que trata do uso das Tecnologias Digitais de Informação e Comunicação (TDIC) na prática docente, especificamente com uso de redes sociais [SOUZA, 2015]. Nesta, concluiu-se, através de levantamento do estado da arte, que a aprendizagem colaborativa tem sido recorrente na escolha de pesquisadores para subsidiar teoricamente o processo de análise dos dados coletados, em muitos casos apontada como proveniente da teoria vygotskyana. Porém, compreende-se que a colaboração também ocorre independente de recursos tecnológicos, tornando-se, portanto, insuficiente para servir de aporte a práticas docentes presenciais que exploram as TDIC e as informações existentes na web. Destaca-se, portanto, a relevância da abordagem conectivista [SIEMENS, 2004], que tem como foco a mudança de paradigma no estilo de aprendizagem em sala de aula, indo além do espaço físico ao se apropriar dos inúmeros softwares e recursos online e da facilidade de acesso para a construção e partilha do conhecimento.

Portanto, este trabalho visa apresentar e discutir uma experiência com uso da plataforma de rede social Facebook, cuja problemática está situada na forma como o professor pode se apropriar da convergência de recursos midiáticos proporcionada pelas redes sociais online para potencializar a participação e interação dos estudantes. Serão analisados os resultados dessa prática sob a ótica dos futuros docentes, verificando as relações entre esta experiência e suas futuras práticas com o uso das TDIC.

\section{Aprendizagem colaborativa e a construção coletiva do conhecimento}

Vygotsky [2008] compreende a aprendizagem como um processo dialético, no qual o aprendiz é um ser ativo, real, concreto, histórico, em permanente transformação, diálogo e interação com tudo o que o cerca. Esse homem é formado dentro de um ambiente cultural definido historicamente e, portanto, é um produto das ações sociais. Nessa perspectiva, o teórico estabelece o fator social como componente fundamental para a análise do desenvolvimento do indivíduo. O meio, o contexto social e as trocas interativas são, nesse sentido, os principais fatores para o desenvolvimento cognitivo do indivíduo, imprescindíveis para a concretização da aprendizagem. Assim, tudo está diretamente relacionado às interações do indivíduo com seu meio, o qual é permeado pela cultura midiática, digital e convergente [SANTAELLA, 2003].

Conforme Gallana [2013, p. 13], a aprendizagem colaborativa mediada por computador pode ser definida como a "ação educativa em que dois ou mais sujeitos constroem o seu conhecimento, baseados na discussão e reflexão de determinado assunto, onde os processos de ensino e aprendizagem são mediados por computadores e outras tecnologias de comunicação". Porém, embora intrínseca ao universo da cibercultura, a aprendizagem colaborativa não se faz exclusivamente nesse ambiente, nem apenas a partir da mediação tecnológica. Para Bohn [2010, p. 67], "a colaboração é um ato social e requer, portanto, todos os tipos de interação humana" e pode ocorrer em locais diversos do ambiente de ensino formal, mas que podem ser organizados para esse fim, como ocorre em comunidades e redes sociais. Dessa forma, a participação e interação do indivíduo em ambientes virtuais "está diretamente associada ao conceito de aprendizagem colaborativa, implicando, por sua vez, relação de interação entre os membros de uma comunidade virtual de aprendizagem" [BOHN, 2010, p. 57]. 
Assim, embora o diálogo e a interação sejam fundamentais para a aprendizagem colaborativa, isso não basta para sua eficácia, é preciso haver expansão e diversificação nas formas e contextos nas quais ela se desenvolve, já que estar junto fisicamente ou fazer parte de um mesmo grupo nem sempre significa interação. Ainda, faz-se necessário considerar algumas necessidades do processo de construção do conhecimento: responsabilidade, iniciativa, flexibilidade de mudança de papéis e rápida adaptação a máquinas e ferramentas e formas de trabalho que envolvem equipes interdisciplinares e heterogêneas [LIBÂNEO, 2011, p. 23].

Isso implica mudança nos paradigmas metodológicos, como sugerem as Diretrizes Curriculares Nacionais da Educação Básica, pois enquanto "[...] a escola se prende às características de metodologias tradicionais [...], as características de seus estudantes requerem outros processos e procedimentos, nos quais aprender, ensinar, pesquisar, investigar, avaliar ocorrem de modo indissociável" [BRASIL, 2013, p. 25]. Perceber tais mudanças no perfil do alunado atual - capaz de aprender e absorver conhecimentos de forma diferente daquele das gerações anteriores - é fundamental. Ainda, ressalta-se, não basta utilizar o computador pelo computador, é preciso que o princípio de inserção das tecnologias esteja norteado pelo trabalho em conjunto, pela aprendizagem interativa, pela conexão entre saberes, entre conteúdos e entre múltiplas mídias.

É importante que se atente para esse desejo da geração atual de permanecer conectado, pois evidencia uma necessidade de diálogo, de construção de novas ideias em colaboração com seus pares; aproveitando-se dessa demanda, o professor pode utilizar os processos comunicacionais promovidos nas redes sociais como instrumentos em benefício da construção de novos métodos de ensino, capazes não apenas de motivar a participação, mas também de estender os limites do processo de aquisição do conhecimento formal, extrapolando a sala de aula e os muros da escola [SIBILIA, 2009]. Isso porque é no universo das informações, no uso de plataformas múltiplas, nas conexões entre todos - na e além da escola - que se tecem os conhecimentos [GALLANA, 2013].

Normalmente associa-se a aquisição do conhecimento à aprendizagem formal, afirma Siemens [2004], porém esse é um processo que pode ocorrer na aprendizagem informal, através da experimentação, da reflexão e do diálogo. Isso porque a aprendizagem não ocorre à margem das nossas vivências, mas é contínua; para Siemens, escolas precisam adotar a visão de aprendizagem como algo que vai além do domínio formal, que pode estar presente em todas as áreas da vida e ocorrer a qualquer momento, em qualquer lugar, formalmente ou não. Nesse caso, são as conexões que nos permitem aprender a aprender, pois "o conectivismo tem o processo voltado ao indivíduo, não de uma forma individualista, mas como resultado das conexões estabelecidas em redes sociais" [RENÓ; VERSUTI; RENÓ, 2012, p. 58].

Seguindo o princípio das redes, o conectivismo busca definir os processos cognitivos e de aprendizagem, enxergando suas estruturas como elos que vão se acumulando, promovendo novos padrões, novas formas, novas conexões, de maneira que, a partir de um conhecimento é possível construir outros novos, associando-os a informações posteriores. Assim, o conhecimento não fica estagnado, devido à maior quantidade de conexões que surgem a partir das interações estabelecidas pelo indivíduo.

Com o conectivismo, tem-se a "aplicação do princípio das redes para definir tanto o conhecimento como o processo de aprendizagem" [RENÓ; VERSUTI; RENÓ, 2012, p. 61], o que justifica sua relevância para a fundamentação teórica de uma aprendizagem 
em rede, pois considerar a troca de conhecimento entre atores sociais como um caminho para o conhecimento. Portanto, esta é uma proposta que prioriza a aprendizagem dialógica, estabelecida a partir da conexão entre as diversas fontes de informação disponíveis (formais ou não), onde a construção do conhecimento ocorre continuamente. Para Mattar [2013], a aprendizagem passa de um processo sob controle do indivíduo (individualista) para aquele que "está também fora de nós, em outras pessoas, em uma organização ou em um banco de dados [...]" (p. 56).

\section{Metodologia e análise}

O método de abordagem da pesquisa estabelecido foi o da Pesquisa-formação, que, conforme Longarezi e Silva (2008, p. 4056), caracteriza-se como uma forma de se fazer ciência em que "o pesquisador sai da clausura de seu laboratório e vai atrás dos problemas do professorado, trabalhando com ele para a solução desses mesmos problemas de forma conjunta e cooperativa". Trata-se de um modelo em que o pesquisador não é neutro, mas que reconhece as inúmeras relações envolvidas na escola, enquanto local de realização da prática docente.

A delimitação por este método deu-se pela "implicação do pesquisador com o campo de pesquisa, construindo juntamente com os sujeitos envolvidos o conhecimento e o próprio método" (SANTOS, 2005, p. 92), quando o pesquisador é sujeito e objeto (NÓVOA, 2004), envolvido na reflexão acerca de sua práxis, o que implica no redimensionamento do papel docente e na formação de um professor crítico (LONGAREZI; SILVA, 2008), que articula pesquisa e ação, o que pressupõe mudanças não apenas das práticas, mas, principalmente, dos sujeitos em formação.

Nesse caso, foi possível desenvolver, ao longo de uma disciplina de graduação de uma Universidade Federal, uma proposta que utiliza uma rede social como ambiente de aprendizagem facilitador e enriquecedor da prática pedagógica. Participaram da pesquisa dezessete estudantes matriculados no curso, os quais são oriundos de cursos diferentes, uma vez que a disciplina é de caráter eletivo. Porém, foram entrevistados apenas os alunos de cursos de licenciatura, a fim de verificar junto a esses os resultados do uso da proposta do conectivismo entre os futuros docentes.

Uma vez que a disciplina faz parte da grade de um departamento ligado à licenciatura e a pesquisa abrange a área de formação de educadores, interessou a esta pesquisadora conhecer os pensares, as opiniões e a visão dos futuros docentes integrantes da turma acerca do uso das TDIC (e não apenas das redes sociais) na prática metodológica e se esta implicou, de alguma forma, em mudanças nessa visão. Isso porque as redes, como espaços favoráveis ao compartilhamento da informação, podem também funcionar como ambiente fértil para o desenvolvimento e inovação pedagógica, criando o contexto necessário à aprendizagem colaborativa, pela partilha de conteúdos em múltiplos suportes (SOUZA; SCHNEIDER, 2014). A escolha pelo Facebook partiu da necessidade de que essa plataforma de rede social servisse como um ambiente online para comunicação e exploração de recursos de apoio à aprendizagem e, também, pelo fácil acesso (apenas um estudante não possuía perfil ativo).

Criou-se um grupo fechado, onde foram postadas atividades propostas pela professora, às quais os alunos respondiam, liam as colocações dos colegas e faziam 
comentários; neste ambiente também foram disponibilizados todos os materiais utilizados em sala (textos, slides, etc.). Foram propostos fóruns de discussão, utilizando ora textos, ora vídeos e links, cujos assuntos versaram não apenas sobre conteúdos curriculares como também sobre temáticas sociais. Além disso, foi possível desenvolver textos cometivos, listas de exercícios, complementação de leitura (mediante links externos de acesso ao conteúdo e leitura de imagens, dentre outras atividades, a fim de proporcionar experiências que "ultrapassem tais situações, analisando a utilização da rede social como recurso didático e ferramenta de apoio ao processo de ensino e aprendizagem" (SOUZA; SCHNEIDER, 2013, p. 9). Os dados da pesquisa e todo o relato da experiência estão disponíveis na dissertação de Mestrado de que trata este artigo [SOUZA, 2015].

Ao final da disciplina, os estudantes responderam a um questionário com perguntas abertas e fechadas, fornecendo dados sobre a proposta realizada, permitindo que se analisassem suas percepções iniciais e finais, sua frequência de acesso, os recursos mais utilizados, as dificuldades encontradas, etc. Dentre os alunos matriculados, sete eram oriundos de cursos de licenciatura. Esses foram convidados a contribuir com uma entrevista semiestruturada, mediante o Termo de Responsabilidade de Pesquisa, que versou sobre o uso das TDIC na educação, sobre as teorias de aprendizagem e comunicação em rede e sobre a experiência com uso do Facebook.

Neste artigo, recorta-se o viés das teorias para aprendizagem e comunicação em rede, restringindo-se o foco das análises a este escopo. Nessa perspectiva, buscou-se saber como os licenciandos enxergam essa mudança no processo de ensino e quais as situações de aprendizagem vivenciadas por eles em sua formação inicial que utilizassem as TDIC. Para os estudantes: "[...] a teoria e a prática é um pouco distante e o que a gente aprende aqui muitas vezes não vai colocar em prática na sala de aula" [ALFA].

[...] a universidade está muito presa não à prática e mais à teoria e isso dificulta porque a gente tem muitos alunos que eles são mais elétricos e aprendem mais na prática do que na teoria. Um dos maiores problemas da universidade é esse. [...] [ÔMICRON].

Eu vim de escola pública e não tenho base. Estou no ensino superior mas sem base nenhuma do ensino básico. Os professores não eram muito presentes, não ensinavam com novos métodos, não tinha aquela dinâmica com a turma. Ele chegava, passava o conteúdo e alguns nem explicavam direito [OMEGA].

Considerando a formação de futuros docentes, é um paradoxo que a prática esteja distante da realidade, afinal, como prepará-los para o exercício da docência (o que implica prática), sem oferecer subsídios para essa base? Professores, em quaisquer níveis de ensino, devem buscar aproximar o discurso da prática, não apenas por estarem sujeitos à apreciação dos alunos na sua avaliação, mas, principalmente, porque o processo dialógico que perpassa a relação professor-aluno é fundamental para uma prática eficiente. Falhas nesse processo, como evidenciou o aluno Omega, são levadas para toda a sua vida acadêmica.

Em relação às teorias de aprendizagem relacionadas ao objeto desta pesquisa e discutidas neste trabalho, a colaboração foi apresentada como a principal destas, tendo como base a teoria vygotskyana, por sua concepção dialética, onde o aluno é um ser 
ativos, real, transformação constante e em diálogo com o mundo que o cerca. Para Palloff e Pratt [2004], quer em ambientes online, quer em sala de aula presencial, a atividade colaborativa é o cerne do curso centrado no aluno e pode ser observada quando ele passa também a refletir sobre a aplicação à sua vida de algo que aprendeu ou sobre o significado de alguma coisa que leu nesses ambientes. Para os estudantes, a experiência de colaboração mediante uso do Facebook esteve fortemente relacionada às trocas de experiências, esclarecimento de dúvidas e desenvolvimento de atividades:

Eu fazia muitos comentários, havia muitas discussões, eu gostava mesmo de ver o que o colega estava vendo, se eu estava vendo de uma forma errada. [...] eu aprendo muito mais com erro que com acertos, porque o erro fica persistindo na cabeça da gente...ah, eu deveria ter feito de outra forma [ÉPSILON].

[...] pude ter acesso ao que você fala, às vezes isso influencia no que eu formular. Então isso é essencial, porque às vezes, no caso de uma prova, de uma atividade, o professor pega e só tem acesso pra ele. A gente fica curioso em saber o que ele escreveu, a gente não tem acesso [...] [ÔMICRON].

Pedir ao aluno que responda às atividades, que comente as postagens dos colegas é o passo inicial para fomentar o diálogo entre estudantes; é, principalmente, torná-los participantes do processo avaliativo. Os depoimentos destacam o valor da aprendizagem online ao permitir que os alunos tenham tempo de refletir não só sobre o material que estudam, mas também sobre as ideias do outro e faz com que percebam que a aprendizagem não ocorre somente pela interação com o professor, mas que é importante saber o que o outro tem a dizer, como ele enxerga determinada situação, como realiza suas tarefas.

De acordo com a percepção de Gallana [2013], colaboração é uma ação educativa em que os sujeitos constroem o seu conhecimento a partir de discussões e reflexões sobre determinado assunto, sob a mediação de computadores e outras tecnologias de comunicação ou não. Mas não se resume a isso, ela vai além da simples troca de informação e precisa promover parcerias entre todos na busca por resultados que não poderiam ser alcançados por indivíduos isolados.

Assim, buscou-se algum indício de atividades que tenham atendido a esse princípio, que tenham promovido parcerias entre os estudantes na busca por objetivos comuns. Destacam-se, nesse quesito, as atividades realizadas em grupo para a realização de seminários. Como os alunos eram oriundos de cursos e turnos diversos, a saída encontrada por eles foi estabelecer o Facebook como local de articulação e distribuição de tarefas. Sobre esta experiência, os licenciandos discorrem que:

Geralmente a gente se organizava na biblioteca, num curto espaço de tempo. Mas na rede social mesmo é que a gente conversava mais. Houve divisão de trabalho, a gente discutia bastante o assunto, trocava informação [ÉPSILON].

[...] nem todos os alunos tinham esse tempo para se reunir e quando tinha trabalho em grupo, em dupla, cada um tinha a sua parte, nós 


\begin{abstract}
juntávamos e todos liam o material inteiro [...], geralmente eu respondia à noite, bem tranquilo, tinha à mão livros, o google, fora as aulas que estavam postadas também. Eu interagia bem com os colegas, a gente se comunicava pelo Face mesmo, em relação ao que cada um ia falar, revisão do trabalho, o que cada um ia fazer. Acredito que não pesou, não ficou sobrecarregado para ninguém, porque foi tudo dividido, um escrevia, passava para o outro [ALFA].
\end{abstract}

Os alunos conseguiram estabelecer uma relação harmoniosa para a resolução de um objetivo comum: conciliar os horários entre os integrantes dos grupos e desenvolver uma boa apresentação, utilizando o espaço de aprendizagem para esse fim, estabelecendo as mesmas relações em equipe no ambiente online que poderiam ser desenvolvidas presencialmente. Isso porque o trabalho em equipe promove o engajamento entre seus membros, a troca de informações, maior flexibilidade e menos formalidade ou rivalidade. Através da utilização da plataforma, foi possível desenvolver atividades onde todos participaram, através da exploração de seus diversos recursos, onde os alunos compartilharam não apenas informações e arquivos, mas dúvidas, anseios e sucessos, graças às possiblidades de conexão em rede.

Acerca do conectivismo, compreende-se, com base na proposta elencada por Downes e Siemens [2004], que a aprendizagem deve ir além do domínio formal, pois diz respeito à abundância de recursos e informações disponíveis na web, presentes em todas as áreas da vida e que podem ocorrer a partir das conexões entre informações, conceitos e saberes. A maior preocupação no decorrer da disciplina foi explorar os mais variados recursos disponíveis na web, não apenas no Facebook.

A intenção foi evidenciar que não se deve limitar o conhecimento e informações àqueles disponibilizadas pelo livro didático, é possível apresentar e avaliar mais do que o conhecimento que os alunos têm do conteúdo por ele ensinado, inclusive mostrando como selecionar, utilizar e avaliar os conteúdos e informações disponíveis. Esse trabalho favorece o desenvolvimento de habilidades importantes, como a análise de informações de fontes diversas, a escolha de argumentos, a validação de informações, a resolução de problemas e aplicação do que foi aprendido. Sob tal perspectiva, os alunos foram convidados a refletir sobre a experiência vivenciada:

É importante usar todos os recursos, desde a própria televisão, cinema, filmes, todos os recursos podem ajudar, até porque na sociedade atual, com a velocidade, a rapidez, atrair o aluno é complicado. Ficar só falando e falando não ajuda. Tem que trazer muitos recursos [ÉPSILON].

Tecnologias motivam bem, tem [...] aplicativo para tudo, que ajuda na pronúncia, por exemplo, fonética do inglês, ele já dá a pronúncia perfeita, então tecnologia está essencial. Não sei porque não usam... muitos professores não sabem muito sobre a tecnologia de hoje, aí barra o aluno, não leva além [ÔMICRON].

Destaca-se o depoimento muito pertinente de Épsilon, que não restringe o uso de recursos e conteúdos didáticos àqueles veiculados na web, mas aponta o uso de mídias de 
massa, como a televisão, o cinema e os vídeos elaborados especificamente para uso escolar, como estratégia de atrair a atenção do aluno.

Ômicron questiona-se por que os demais professores não fazem uso deles, já que são tão acessíveis, apresentando ele mesmo a resposta: professores mais antigos não sabem muito sobre a tecnologia. Seria uma tendência relacionada à idade? Um típico caso de indivíduos imigrantes digitais, nascidos antes da disseminação das TDIC? O licenciando responde: "Acho que a idade não influencia nisso, acho que é formação. Tem professor que chegou ali parou, não dá continuidade a outra coisa, não faz um curso diferente..."

Por isso, o professor precisa, ele mesmo, se tornar usuário ativo da web e das plataformas e softwares sociais, buscando conhecer e explorar suas funcionalidades, os sites e recursos específicos para o ensino, caso contrário, é impossível aliar os recursos disponíveis na web ao conteúdo formal da escola com sucesso. Sem planejamento seguro e conhecimento acerca de metodologia específica para a aprendizagem em rede, certamente o docente tenderá a se manter em sua zona de conforto, trabalhando com métodos, recursos e técnicas com os quais esteja familiarizado.

É lamentável concordar com o que Imbernón diz [2006, p. 41]: “o tipo de formação inicial que os professores costumam receber não oferece preparo suficiente para aplicar uma nova metodologia, nem para aplicar métodos desenvolvidos teoricamente na prática de sala de aula". É na formação inicial que o docente precisa conhecer novos métodos de ensino, por isso, o professor deve possuir domínio pedagógico, inclusive acerca das novas linguagens e tecnologias. Por isso, cada professor atuante na formação docente deve ser um exemplo para o licenciando, a partir de sua própria prática.

Procurando saber o que estes licenciandos absorveram da experiência direta com teorias que exploram a aprendizagem e comunicação em rede e se eles pretendem aplicála (ou já aplicam, caso já exerçam a profissão), obtiveram-se os depoimentos: "Eu usaria, acho que é muito importante que o aluno tenha acesso a meios tecnológicos. Tem muitas escolas que já fazem, os alunos ganharam tablets. Tem casos que os professores falam que os alunos melhoraram bastante" (ALFA).

Futuramente, pretendo usar em meu estágio e eu gostaria muito de usar o facebook, mas tem essa questão: vamos ver as condições dos alunos, porque nem sempre todos tem as condições, nem todos têm computador, smartphone. Mas como professor, eu pretendo com certeza utilizar, [...] pois eu acho que os alunos não têm esse acesso e no Facebook eu tenho essa chance (ÔMICRON).

Eu gostei muito da proposta, não foi à toa que quando eu estava fazendo monitoria eu também utilizei o Facebook, fiz um grupo para que os alunos também pudessem interagir, porque eu via que na sala de aula também tinha muitos problemas, o aluno não perguntava nada ao professor e no grupo ele perguntava (EPSILON).

Segundo os depoimentos, a proposta metodológica alcançou boa receptividade entre eles, já que três pretendem utilizar algo semelhante. Suas falas revelam ainda maturidade em relação à forma de utilização as TDIC em suas práticas, pois partem de 
suas próprias reflexões sobre os pontos negativos do processo: considerar a realidade dos alunos, se possuem ou não internet, computador ou smartphones, inclusive apresentando conteúdos extracurriculares (cultura estrangeira), considerando que os alunos, geralmente, não possuem acesso a esse relevante conteúdo (possivelmente uma ausência percebida em sua própria formação). Uma boa proposta metodológica, aplicada a uma turma em processo de formação, somente poderá se apresentar como realmente eficaz quando seus frutos podem ser vistos, quer em mudanças de olhares e paradigmas préestabelecidos, quer em ações motivadas a partir dela.

Diante do exposto, fica evidente a necessidade de reflexão acerca da formação que se faz na Universidade, para que a experiência obtida nessa fase seja capaz de motivar futuros docentes ao exercício da prática, a partir de metodologias diferenciadas, pois os alunos que enfrentam dificuldades nessa fase de formação inicial certamente sentirão maior dificuldade em prosseguir na profissão com qualidade.

\section{Considerações finais}

A conexão constante do jovem em redes sociais evidencia uma necessidade de diálogo, de construção de novas ideias em colaboração com seus pares e o professor pode explorar essa demanda em benefício da sua práxis, não apenas motivando a participação, mas estendendo os limites do processo de aquisição do conhecimento formal, extrapolando a sala de aula e os muros da escola. Para o conectivismo, é no universo das informações, no uso de plataformas múltiplas, nas conexões entre todos - na e além da escola - que se tecem os conhecimentos.

Conforme as análises feitas a partir dos depoimentos dos alunos em relação à aprendizagem em rede, como também das discussões empreendidas a partir das atividades realizadas no grupo da turma no Facebook, considera-se que o uso do Facebook como ambiente de aprendizagem proporcionou essa conexão entre conteúdos, informações e ambientes de estudo, gerando novos conhecimentos a partir do contato e interação entre os participantes. Além disso, observou-se, nos trabalhos em grupo, o estabelecimento de estratégias para alcançar objetivos comuns, diante do desafio de preparar e distribuir as tarefas entre os integrantes do grupo, verificar o andamento do processo, conhecer e integrar as partes a fim de empreender a coesão entre integrantes de cursos e turnos diferenciados. A utilização do Facebook para empreender essas tarefas foi a solução encontrada, cujos resultados foram explicitados nas falas dos licenciandos e verificada pela docente nas apresentações dos seminários em sala de aula.

Em educação utilizamos tecnologias a partir do momento em que lançamos mão dos vários recursos e procedimentos auxiliares ao processo pedagógico, inclusive as próprias teorias de aprendizagem para fundamentar a metodologia aplicada são exemplos de tecnologias. O que urge maior discussão é que a relação entre a educação e as TDIC seja, de fato, aplicada na educação superior de forma eficiente, que ela vá além da teoria e que possua um peso maior face às necessidades da sociedade atual.

Ao refletir sobre o uso que a educação pode fazer das TDIC a seu favor, o professor estará oferecendo aos alunos as experiências educacionais que serão necessárias para seu exercício na sociedade moderna, preparando-os para os papéis que lhes serão exigidos. 
V Congresso Brasileiro de Informática na Educação (CBIE 2016)

Anais do XXII Workshop de Informática na Escola (WIE 2016)

\section{Referências}

Bohn, V. C. R. Comunidades de pratica na formação docente: aprendendo a usar ferramentas da web 2.0. Dissertação de Mestrado. Universidade Federal de Minas Gerais, 2010.

Castells, M. Sociedade em Rede. Tradução: Roneide Venâncio Majer; $6^{a}$ ed. São Paulo: Paz e Terra, 1999.

Gallana, L. M. R. Facebook: um espaço de colaboração para a troca de experiências com uso de tecnologias em sala de aula. Dissertação de Mestrado. Universidade Estadual de Campinas - SP, 2013.

Imbernón, F. Formação docente e profissional: formar-se para a mudança e a incerteza. $6^{a}$ ed. São Paulo: Cortez, 2006.

Libâneo, J. C. Adeus professor, adeus professora?: novas exigências educacionais e profissão docente. São Paulo: Cortez, 2011.

Mattar, J. Web 2.0 e redes sociais na educação. São Paulo: Artesanato Educacional, 2013.

Mota, J. C. "Da web 2.0 ao e-learning 2.0: aprender na rede". Dissertação de mestrado. Universidade Aberta. Lisboa, Portugal, 2009.

Palloff, R. M.; Pratt, K. O aluno virtual: um guia para trabalhar com estudantes on-line. Trad. Vinícius Figueira. Porto Alegre: Artmed, 2004.

Renó, D. P., Versuti, A., Renó, L. T. L. Transmediação e conectivismo: contemporaneidade para a educação. In: Linhares, R. N., Lucena, S. Versuti, A. (org.) "As redes sociais e seu impacto na cultura e na educação do século XXI". Fortaleza: Edições UFC, 2012.

Santaella, L. Culturas e artes do pós-humano: da cultura das mídias à cibercultura. São Paulo: Paulus, 2003.

Schön, D. A. Educando o profissional reflexivo: um novo design para o ensino e a aprendizagem. Tradução Roberto Cataldo Costa. Porto Alegre: Artmed, 2000.

Sibilia, P. "Redes ou paredes: a escola em tempos de dispersão". Trad. Vera Ribeiro. Rio de Janeiro: Contraponto, 2012.

Siemens, G. "Conectivismo: Uma Teoria de Aprendizagem para a Idade Digital". Trad. Bruno Leite, 2004. Disponível em: http://pt.scribd.com/doc/66317606/Conectivismouma-Teoria-Para-a-Era-Digital. Acessado em: 04.02.2014.

Souza, A. A. N. Uso do Facebook como ambiente de aprendizagem: análise da praxis presencial mediada pelo conectivismo pedagógico. Dissertação de mestrado. Universidade Federal de Sergipe. São Cristóvão: SE, 2015.

Souza; Schneider, H. N. O Facebook como espaço de interação, colaboração e aprendizagem: uma reflexão sob a perspectiva discente. In: "Anais do XX Workshop de Informática na Escola”. Dourados, MS, 2014.

. Uso do Facebook como Recurso de Avaliação da Aprendizagem. In: “Anais do XIX Workshop de Informática na Escola”. Campinas, SP, 2013.

Vygotsky, L. S. Pensamento e Linguagem. 4ª ed. São Paulo: Martins Fontes, 2008. 